Original Article

Received/Accepted

Dates

19.03.2021/12.04.2021

DOI

10.52096/jsrbs.6.1.7.13.8
Journal of Social Research and Behavioral Sciences

Sosyal Araştırmalar ve Davranış Bilimleri Dergisi

ISSN:2149-178X

Volume: 7 Issue: 13 Year: 2021

\title{
Kronik Hastalıkların Tedavi ve Bakımında Umut Terapisinin Kullanımı1
}

Şerife Bilge DURAN

Akdeniz Üniversitesi Sağlık Bilimleri Enstitüsü Ruh Sağlığı ve Psikiyatri Hemşireliği YL Öğrencisi

ORCID: 0000-0001-9343-8789

bilgemavi975@gmail.com

Dr. Öğr. Üyesi İlkay KESER

Akdeniz Üniversitesi Hemşirelik Fakültesi

Psikiyatri Hemşireliği Anabilim dalı

ORCID: 0000-0001-6595-4188

i.k.keser@gmail.com

\section{Özet}

Kronik hastalığa sahip olan bireyler, hastalığın beraberinde getirdiği biyolojik değişimlere ek olarak ekonomik güçlükler, aile ilişkilerinde bozulma, sosyal aktivitelerde azalma, yalnızlık hissetme gibi birçok güçlükle karşılaşabilmektedir. Yaşanan bu güçlükler, bireylerin umut düzeylerinde azalmaya neden olmaktadır. Bireyin umudunun azalması ile tedaviye uyumu ve yaşam kalitesi olumsuz etkilenmektedir. Umudu güçlendirmeye yönelik uygulanabilecek müdahaleler arasında Snyder'in umut teorisine dayanan umut terapisi yer almaktadır. Umut terapisi, kronik hastalıklardan ruhsal bozukluklara kadar birçok hastalıkta uygulanabileceği gibi sağlıklı bireylerin ruh sağlığını koruma ve geliştirmek için uygulanılabilir. Bireylerin sağlığını koruma ve geliştirmede önemli rol oynayan tüm sağlı profesyonelleri tedavi ve bakımı planlarken, bireyi bütüncül ele almalıdır. Bireyin var olan yaşam arzusu, ulaşmak istediği hedefleri, hedefine ulaşmak için var olan motivasyonu ve umut kaynaklarını belirlemeli ve bireyi olumlu yönde desteklemelidir. Bu derleme çalışmasında, Snyder'in umut teorisinde belirtilen aşamalara ve uygulama örneklerine yer verilerek, kronik hastalığa sahip bireylerin bakım ve

\footnotetext{
${ }^{1} \mathrm{Bu}$ çalışma, 25- 27 Haziran 2021 tarihinde yapılan SADAB IX. Uluslararası Sosyal Araştırmalar ve Davranış Bilimleri Sempozyumu'nda sözel bildiri olarak sunulmuştur.
} 
tedavisinde umudu arttırma ve geliştirmede umut terapisinin kullanımına dikkat çekmek, bu konuda sağlık profesyonellerinde farkındalık oluşturmak amaçlanmıştır.

Anahtar Kelimeler: kronik hastalığa sahip olmak, umut, umut terapi

\title{
In the Treatment and Care of Chronic Diseases Use of Hope Therapy
}

\begin{abstract}
In addition to the biological changes brought about by the disease, individuals with chronic disease may encounter many difficulties such as economic difficulties, deterioration in family relationships, decrease in social activities, and feeling lonely. These difficulties cause a decrease in the hope levels of individuals. With the decrease of hope of the individual, adherence to treatment and quality of life are adversely affected. Among the interventions that can be applied to strengthen hope is hope therapy based on Snyder's theory of hope. Hope therapy can be applied to many diseases from chronic diseases to mental disorders as well as to protect and improve the mental health of healthy individuals. All health professionals, who play an important role in protecting and improving the health of individuals, should consider the individual holistically while planning treatment and care. The individual's desire for life should determine the goals he wants to achieve, the motivation and sources of hope to reach his goal and should support the individual in a positive way. In this review study, it is aimed to draw attention to the use of hope therapy in increasing and developing hope in the care and treatment of individuals with chronic diseases, and to raise awareness in health professionals on this subject by giving place to the stages and application examples specified in Snyder's theory of hope.
\end{abstract}

Keywords: having chronic illness, hope, hope therapy

\section{Giriş}

Kronik hastalıklar, bireyleri fiziksel ve ruhsal açıdan etkilemekle beraber bireylerin sosyal çevresini, yaşamın pek çok alanını, bütüncül olarak yaşam kalitesini etkileme potansiyeline sahiptir. Hastalığın etkilediği biyolojik yapı, hastalığın türü, süresi, bireylerin problem çözme ve baş etme kapasitesi gibi faktörler hastalığın etki derecesini değiştirmektedir. Hem fiziksel hem de ruhsal hastalıklar arasında bulunan kronik hastalıklarda bu etki yoğun olarak görülmektedir. Dünya Sağlık Örgütü (WHO) (2005) kronik hastalıkları "kalıc1, sekel bırakabilen, geri dönüşü 
olmayan patolojik değişikliklerden kaynaklanan, uzun bir tıbbi süreç içerisinde takip edilmesi gereken hastalıklar" olarak tanımlamıştır. Kronik hastalıkların meydana getirdiği semptomlar doğrultusunda ağrı, acı ve yorgunluk gibi çeşitli durumlarla karşılaşabilir. Hastalığa özgü semptomlara ek olarak bireyler yoğun stres altında hissedebilir. Bireyler hayal kırıklığı, öfke, umutsuzluktur (Başaran vd., 2016), depresyon (Yıldırım vd., 2013; El Filali vd., 2017; Ravaghi vd., 2017), ve anksiyete (Yıldırım vd., 2013; El Filali vd., 2017) gibi çeşitli psikolojik güçlükler yaşayabilirler. Diğer taraftan kronik hastalıklar bireyin sosyal yaşamında da çeşitli etkiler yaratabilir. Birey arkadaş ilişkilerinden, sosyal aktivitelerden ve çalışma yaşamından çekilebilir (Özcan vd., 2000; Okanlı ve Karabulutlu, 2011). Hastalığın teşhisi, tedavisi ve tıbbi malzeme gereksinimleri gibi sebeplerden dolayı ekonomik güçlükler yaşayabilir. Bu bağlamda, bireylerin karşılaştıkları güçlüklerle baş etmesi ve tedavi süreçlerine uyumlanması psikososyal müdahalelerin yapılmasını gerekli kılmaktadır.

Umut terapisi bireylerin yaşamlarında hedefler belirlemesine, belirlediği hedeflere ulaşmak için yollar bulup, karşılaştığı engellere karşı bu yollara ek alternatif yollar bulmasına yardımcı olan psikososyal bir müdahaledir. Umut terapisinde bireyin yaşamında umudu arttırmak hedeflenmiştir. Umut düzeyinin yüksekliği bireylerin yaşam doyumunu arttırmada önem taşımaktadır (Çetrez İşcan ve Malkoç, 2016).Bireyin kendisini güvende hissetmesini ve gerçekle ilişki kurmasını sağlayan, motivasyonunu artıran, hastalık durumunda karamsarlık veya çaresizlik duygularını önleyen, tedaviye uyuma katkı sağlayan etkili bir baş etme mekanizması olarak görülmektedir (Ottaviani vd., 2014; Cutcliffe ve Herth., 2002) Hastaların umut seviyesi arttıkça tedaviye uyumları artmakta ve bunun sonucunda hastalık semptomlarının azalmasında etkili olabilmektedir (Taşkın Yılmaz vd.,2020). Bu bağlamda yapılan derleme çalışmasında, umut terapisinin kavramlarını tanımlayıp, uygulanabilecek bireyleri incelemek ve ülkemizde kullanımını arttırmak için farkındalık oluşturmak amaçlanmıştır.

\section{Geçmişten Günümüze Kavram Olarak Umut}

Geçmişten günümüze kadar umut kavramı ile ilgili farklı tanımlamalar yapılmış ve umutla ilişkili faktörler değerlendirilmeye çalışılmıştır (Öz, 2010). Yunan mitolojisinde umut, Pandora'nın kutusunda yer alan kötülüklerden biri olarak anılmış ve insanlığ cezalandırmak için tanrılar tarafından gönderildiğine inanılmıştır. Yahudi-Hıristiyan geleneğinde ise umut bir erdem, 
Tanrı'dan manevi bir hediye, tartışmasız iyi bir şey olarak kavramsallaştırılmıştır (Schrank ve Grant, 2011).

Umut kavramının kuramsal çalışmaları 13. yy'a dayanmaktadır. 13. yy'da din bilimcisi Aquinas sonraki yüzyıllarda Hume ve Kant gibi düşünürler umudu insanın doğasında var olan temel bir duygu olarak ele almışlardır (Akman ve Korkut, 1993). Miller, umudu yaşamda bir iç güdü olarak tanımlamış, insanları incinmekten koruyan ve dolayısıyla potansiyellerini göstermelerinde kolaylaştırıcı bir etmen olduğunu belirtmiştir (Miller, 1985). Umut, Türk Dil Kurumu'na göre ummaktan doğan duygu ve olması beklenen ve olacağı düşünülen şeydir.

Umut temel bir kişilik özelliği olarak kabul edilmiş (Synder vd., 1991) ve insan yaşamında temel bir kaynak olarak tanımlanmıştır (Kylma, 2005). Öz 2010'un aktardığına göre Meninger ve Erikson, umudu insan gelişimi için en önemli faktör olarak tanımlamışlardır. Korner ise umudu sağlıklı olmada en önemli kriter olarak belirtmiştir. Bireyin hastalık durumunda umudunun olması, karamsarlığa ve çaresizlik duygusuna kapılmasını önler.

İlerleyen zamanlarda umudun sadece duygusal boyuta sahip olmadığ olduğu ileri sürülmeye başlanmıştır. Frank (1968) duygu ve düşüncenin anlamlı bir karışımı olarak umudu tanımlamış ve umudun iki boyutlu olduğunu ilk defa ileri süren kişi olmuştur. Umudun psikoterapide kullanımının bireyi olumlu etkileyeceğini ve bireyin iyileşmesinin hız kazanacağını belirtmiştir.

\section{Bir Tedavi Yöntemi Olarak Umut Terapisi}

Umut terapisi Snyder'in umut teorisine dayanmaktadır (Sotodeh-Asl vd, 2010; Ghezelseflo ve Esbati, 2013). Snyder vd. 1991'de umudu iki bileşenle ifade etmişlerdir. Bunlar alternatif yollar düşüncesi ve eyleyici düşüncedir.

Umut terapisi kapsamında ilk olarak hedef belirlenmelidir. Bireylerin yaşamlarında, uğrunda çaba göstermeye değer ve özgür iradesiyle seçtiği hedefleri olmalıdır (Frankl, 2020). Hedef, umut teorisinin dayanağı olan bilişsel bir parçadır. Gerçekleşme ihtimali az olan hedeflerin olduğu gibi gerçekleşmesi kesin görünen hedefler de vardır. Kısa süreden uzun süreye kadar gerçekleşebilecek farkl1 derecede hedefler olabilir (Synder, 2000; Snyder vd., 2002) 


\subsection{Eyleyici düşünce (Agency thinks)}

Bireyin, belirlediği hedefe değer verip elde etmek için istek duyması ve hedefe ulaşmak için kendisinde güç hissetmesidir. Bu kavram, geçmiş, şu an ve gelecekte hedefe ulaşmada, başarılı kararlar alabilmeye ilişkin duygu ve düşünceleri kapsamaktadır (Snyder vd., 1991). Eyleyici düşünceler bireyi motive eden, engellerin varlığında yolları planlamada ve uygulamada güç veren düşüncelerdir (Snyder vd., 2002).

Bireyin geçmişte yaşadığı umut deneyimleri ile hedeflere ulaşmada yollar bulabileceğini görmüş olması, gelecekte var olacak hedeflere ulaşmada istek duymasına ve hedefe ulaşmada yollar bulabileceğine karşı kendisinde güven hissetmesine yol açar. Karşılaştığı problemleri çözdükçe, gelecekte yaşayacağı problemleri çözmeye ilişkin kendisinde güç hissedecektir. Bu bağlamda birey umutlu olacaktır (Snyder, 1989).

\subsection{Alternatif Yollar Düşüncesi (Patway thinks)}

Bireyin istediği hedefe ulaşmak için yollar belirleyebilme düşüncesinin varlığını içerir. Alternatif yollar düşünme, bireyin hedefleri doğrultusunda bugünü geleceğe bağlayan yoldur. Birey, şu an olduğu konumunu, olmayı arzuladığı konumu ve istenilen konuma ulaşırken kullanacağı konumu düşünmelidir. Karşısına engeller çıktığında gidebileceği yolları ayrıntılı şekilde planlamalıdır (Cheavens vd., 2006). Karşılaşılan engellerde birey, "başka bir yol bulacağım" diyerek alternatifleri güçlendirir ve yeni çözümler bulabilmesini kolaylaşır (Snyder, 2002).

Umut terapisinde hedefler, eyleyici düşünce ve alternatif yollar düşüncesi karş̧1ıklı olarak birbirlerini etkiler. Uygun hedefler belirleyen birey, hedeflerine ulaştıkça eyleyici düşüncesi artar. Eyleyici düşüncenin artması ile bireyin motivasyonunda yükselme meydana gelir ve yükselen motivasyon ile alternatif yollar düşünme artar (Cheavens vd., 2006). Yapılan bir araştırmada eyleyici düşünce ile alternatif yollar düşüncesi arasında 0.45 ile 0.70 arasında güvenilir korelasyon bulunmuştur (Snyder vd., 1991).

\section{Umut Terapisi Uygulama Basamakları}

Umutlu düşünmeyi artırmak ve hedefe ulaşmak için ilerleme faaliyetlerini geliştirmek amacıyla oluşturulan umut terapisi bireysel görüşmelerin yapıldığı (Mozooni v Ark., 2017; Rahimipour vd., 2015) gibi grup oturumları (Sotodeh-Asl vd, 2010; Shekarabi-Ahari vd., 2012; KhalediSardashti vd., 2018) şeklinde de uygulanabilir. Sekiz oturumda gerçekleşen umut terapisi 60-90 dakika 
arasında sürmektedir. Umut terapisi ilk olarak 2006 yılında Cheavens vd. tarafından bir pilot çalışma olarak 32 bireyle gerçekleştirilmiştir. Bu çalışmada katılımcılara umut terapisi tanıtılmış, araştırmacılar kendi hayatlarından örnekler vererek ilkelerin nasıl uygulanacağına dair bilgi verilmişlerdir. Çalışma kapsamında katılımcılar için hedef oluştururken 5 basamak tanımlamışlardır. Bu basamaklar;

1-Anlamlı, ulaş1labilir hedefler belirleme,

2- hedeflere ulaşmak için birden fazla yol geliştirme,

3-motivasyon kaynaklarını belirleme ve motivasyonu azaltacak herhangi bir duruma karşı koyabilme,

4-hedeflere yönelik ilerlemeyi izleme,

5- hedefleri ve yolları gerektiği gibi değiştirebilme şeklinde tanımlamışlardır.

Pilot çalışmada, protokolün ilk değerlendirmesi olarak tasarlanmıştır ve katılımcılar rastgele olarak tedavi grubuna veya kontrol grubuna atanmıştır. Ölçüm aracı olarak Structured Diagnostic Interviews (SCID-I) kullanılmıştır. Deney grubunun terapisi sonrası umut, yaşamdan anlam bulma ve benlik saygısında artma gözlemlenirken depresyon ve anksiyete puanlarında azalma gerçekleşmiştir (Cheavens vd., 2006). Problem odaklı terapilerin aksine umut terapisi, sorunları önleme veya semptomları ortadan kaldırma yollarına odaklanmak yerine, hedefleri aktif olarak takip edilmesi gereken olumlu sonuçlar olarak çerçeveler.

\section{Umut Terapisi Kimlerde Uygulanır}

Snyder farklı etnik gruplarla yapılan çalışmaların sonucunda umut dolu düşünmenin kalıtsal olmadığını, çocukluktan itibaren öğrenildiğini belirtmiştir. Dolayısıyla umut dolu düşüncenin öğretilebileceği ve artırılabileceğini savunmuştur (Snyder, 2000). Çocuklar kötü olaylarda bile iyi gelecek hayal edebilirler. Snyder bu durumu, agency ve patway'in alışılmadık derecede iyi gelişmiş olmasıyla açıklamıştır (Snyder, 1994). Umut terapisinde çocuğun yaşadığı duruma uygun anlatılar veya hikayeler, çocuklara belirli bir yöntemi açıklamak için yararlı araçlar olabilir ve sorunlar çözülebilir (Snyder vd., 1997). Hikâyede karakter umudunu yitirmeye yakınken bir hedef belirler ve bu hedefe ulaşmak için planlar yapar. Bu durumda çocuklar karakteri model alabilir. Çocukluk döneminde model alabileceği ebeveyn ya da bakıcı olmadığı durumlarda bu karakter işe yaramaktadır. Fiziksel bir engeli olan, travma yaşamış, kronik bir rahatsızlığı olan çocuklarda, 
hikâye yöntemine ek olarak kendi yaşam zorluklarını daha rahat anlatabilmeleri için hikâye yazma tekniği kullanılabilir. Hikâye kullanma tekniği ile çocukların umutları güçlendirilebilir. $\mathrm{Bu}$ teknikle "Çok acıyor, artık dayanamıyorum" gibi yıkıcı düşüncelerde olan çocuk "bundan hoşlanmadım ama buna dayanabilirim” gibi alternatif düşüncelere yönlenir (Snyder, 2000). Umut terapisi AIDS gibi bulaşıcı rahatsızlığa sahip olan (Snyder, 2000), kanser, diyabet (KhalediSardashti vd., 2018), hipertansiyon (Sotodeh- Asl vd., 2010, Mozooni vd., 2017), KBY (Rahimipour vd., 2015) gibi kronik rahatsızlığı olan bireylerde kullanılabilir. Anoreksiya nevroza ve bulimia nevroza gibi yeme bozukluğu yaşayan bireylerde, travma sonrası stres bozukluğu, depresyon (Rahimipour vd., 2015, KhalediSardashti vd., 2018, Movahedi vd., 20115), stres, panik

atak ve anksiyete (Rahimipour vd., 2015) yaşayan bireylere umut terapisi uygulanabilir. Kanser tanısı almış çocukların annelerinde (20), travma sonrası stres bozukluğu tanılı hastaların bakım vericileri (Yousefi vd., 2016) gibi bakım verici rolünde olan bireylere umut terapisi uygulanmıştır. Ayrıca göç etmek zorunda kalan, kültürel ve ekonomik zorluklar yaşayan bireylere, okul yaşamında zorlanmalar yaşayan öğrencilerde, iş yükünün fazla olup zaman kısıtlaması olan ve tükenmişlik yaşayan meslek grubu üyelerinde kullanılabilir (Snyder, 2000). Aynı zamanda toplumun farklı kesimlerinde (Cheavens vd., 2006, Alaeddını vd., 2008), hamile kadınlar (Samavi vd., 2018), evli öğrenciler (Khoshkharam vd., 2011) vb. sağlıklı bireylerin ruh sağlığına etkisini incelemek amacıyla bazı çalışmalar da yapılmıştır.

Literatürde umut terapisi uygulanan bireylerde depresyon (Rahimipour vd., 2015, Khaledi Sardashti vd., 2018), anksiyete, ve stres düzeylerinde (Rahimipour vd., 2015), azalma görülmüş, iyi oluşlarının (Shekarabi-Ahari vd., 2012) arttığı gözlenmiştir.

\section{Kronik Hastalıkların Tedavisinde Umut Terapinin Uygulama Örnekleri}

Ülkemizde umut terapisi ile yapılan çalışmalara rastlanmamakla birlikte uluslararası literatürde kullanımının yaygın olduğu tespit edilmiştir. Yapılan çalışmalarda 8 oturumla gerçekleşen umut terapisi, grup oturumları ve bireysel görüsşmeler şeklinde uygulanmıştır.

Hemodiyaliz tedavisi gören 50 bireyle yapılan çalışmada umut terapisi grup görüşmeleri ile gerçekleşmiş ve 8 oturumda tamamlamışlardır. Yapılan çalışma sonucunda depresyon, anksiyete ve stres puanlarının önemli ölçüde azaldığı ve Umut tedavisinin etkilerinin 1 aya kadar uzun ömürlü olduğu gözlemlenmiştir (Rahimipour vd., 2015). 
Benzer yapılan bir çalışmada Moozani vd. (2017) umut terapisini yoğun bakım ünitelerinde yatışı gerçekleşen unstabil angina tanılı yaşı bireylere (32 kişi) uygulamışlardır. Bireysel görüşmeleri ile gerçekleşen umut terapisini 8 oturumda tamamlamışlardır. Çalışmanın sonucunda Umut terapisinin deney grubundaki depresyon puanlarının 1 ay sonra kontrol grubuna göre anlamlı derecede düşük olduğunu belirtmiş̧lerdir.

Diyabet hastalarıyla yapılan bir çalışmada, 38 birey ile grup görüşmeleri gerçekleşmiş ve 8 oturum tamamlanmıştır. Bireylerin oturumlar sonucunda umut terapisinin kontrol grubuna kıyasla çalışma grubunda müdahale sonrası diyabetik hastalarda umudu önemli ölçüde artırdığı gözlemlenmiştir (Ghazavi vd., 2015).

Yapılan bir başka çalışmada Farhadi vd. (2014) umut terapisini kanser hastaları ve aileleri olmak üzere 42 bireye (kontrol grubunda 16, deney 14 hasta-hasta ailelerinin grup terapisinde 12) uygulamışlardır. Grup görüşmeleri ile gerçekleşen umut terapisini 8 oturumda tamamlamışlardır. Oturumlar sonucunda umut terapisinin kanser hastaları ve ailelerinin kontrol grubuna göre hastaların yaşam kalitelerini olumlu etkilediği belirtilmiştir.

Yapılan çalışmalar (Rahimipour vd., 2015; Moozani vd., 2017; Ghazavi vd., 2015; Farhadi vd., 2014) doğrultusunda kronik hastalıklara sahip bireylere uygulanan umut terapisinin bireylerin yaşam kalitelerini arttığı, depresyon, stres ve anksiyete düzeylerini azalttığı belirtilmektedir. Farklı kronik hastalıkların bakım ve tedavisinde umut terapi kullanımının tercih edildiği ve ruhsal semptomların azaltılmasında olumlu etkisi olduğu görülmektedir. Çalışma sonuçları, kronik hastalıkların bakım ve tedavisinde umut terapi kullanımının ruhsal semptomların azaltılmasında olumlu etkisi olduğu ortaya konulmaktadır.

\section{Sonuç ve Öneriler}

Derleme çalışmasından elde edilen bulgular sonucunda umudun, insan yaşamında önemli bir kavram olduğu, umudu artırmaya yönelik yapılacak müdahalelerin bireylerin kronik hastalık sürecine uyumunu kolaylaştırdığı, iyileşmeyi hızlandırdığı, ruh sağlığını koruma ve iyilik halini sürdürmede önemli bir faktör olduğu söylenebilir. Umut terapisi, kronik hastalıklardan ruhsal bozukluklara kadar birçok hastalıkta uygulanabileceği gibi sağlıklı bireylerin ruh sağlığını koruma ve geliştirmek için uygulanılabilir. Bireylerin sağlığını koruma ve geliştirmede önemli rol oynayan 
tüm sağlık profesyonelleri tedavi ve bakımı planlarken, bireyi bütüncül ele almalıdır. Bireyin var olan yaşam arzusu, ulaşmak istediği hedefleri, hedefine ulaşmak için var olan motivasyonu ve umut kaynaklarını belirlemeli ve bireyi olumlu yönde desteklemelidir. Bu bağlamda ülkemizde kronik hastalığa sahip bireylerin bakım ve tedavisinde, umudu arttırma ve geliştirmede umut terapisinin kullanımının yaygınlaşması, farklı hasta gruplarında uygulanması ve yaygınlaştırılması önerilmektedir.

\section{Kaynakça}

AKMAN, Y., KORKUT F. (1993). Umut ölçeği üzerine bir çalışma. H.Ü. Eğitim Fakültesi Dergisi, 9(9), 193-202.

ALAEDDINI, Z., KAJBAF, MB., MOLAVI H. (2008). The effects of group hope therapy on mental health of female students in Isfahan University. Res Psychol Health, 1(4), 66-76.

BAŞARAN, D., ŞAHIN ALTUN, Ö., KABAN, F., ECDER, T. 2016.mHemodiyaliz hastalarının umutsuzluk düzeylerinin değerlendirilmesi. Nefroloji Hemşireliği Dergisi, 1:9-16.

CHEAVENS, JS., FELDMAN, DB., GUM, A., MICHAEL, ST., SNYDER, CR. (2006). Hope therapy in a community sample: A pilot investigation. Social indicators research, 77(1), 61-78.

CUTCLIFFE, J., HERTH, K. (2002). The concept of hope in nursing 2: hope and mental health nursing. Br J Nurs, 11(13),885-893.

DÜNYA SAĞLIK ÖRGÜTÜ. (2005). Preventing chronic diseases : a vital investment : WHO global report. https://www.who.int/chp/chronic_disease_report/full_report.pdf Erişim tarihi:10.07.2021

EL FILALİI, A., BENTATA Y, ADA N, ONEIB B. (2017). Depression and anxiety disorders in chronic hemodialysis patients and their quality of life: A cross sectional study about 106 cases in the northeast of morocco. Saudi J Kidney Dis Transpl, 28(2),341-348.

FRANK, J. (1968). The role of hope in psychotherapy. Int J Psychiatry, 5(5), 383-395.

FRANKL, V. (2000). İnsanın anlam arayışı. Çeviren: Budak S. 69.basım Ankara: Okuyan Us; 25.

GHEZELSEFLO, M., ESBATİ, M. (2013). Effectiveness of hope-oriented group therapy on improving quality of life in HIV+ male patients. Procedia Soc Behav Sci, 84, 534- 537.

KHALEDISARDASHTI, F., GHAZAV, Z., KESHANI, F., SMAEILZADEH, M. (2018). Effect of hope therapy on the mood status of patients with diabetes. Iran J Nurs Midwifery Res, 23(4), 281-286.

KHOSHKHARAM, N., GOLZARI, M. (2011). Efficacy of hope therapy on the rate of increasing marital satisfaction and change in insecure attachment style in Married University students. J Appl Psychol, 5:2(18), 84-96.

KYLMA, J. (2005). Dynamics of hope in adults living with HIV/AIDS: a substantive theory. JAN, 52(6), 620- 630. 
KYLMÄ, J., JUVAKKA, T., NIKKONEN, M., KORHONEN, T., ISOHANNI, M. (2006). Hope and schizophrenia: an integrative review. J Psychiatr Ment Hlt, 13(6), 651-664.

MILLER, JF. (1985). Hope does not necessary spring eternal sometimes it has to be carefully mined and channeled. AJN, 85, 22-25.

MOORE, SL. (2005). Hope makes a difference. J Psychiatr Ment Hlt, 12(1), 100-105.

MOVAHEDI, M., KARIMINEJAD, K., BABAPOUR KHEIRODIN, J., MOVAHEDI, Y. (2015). The effectiveness of hope therapy base on groups to increase the components of self-esteem and psychological health in depressed people. J Adv Med Biomed Res, 23(98), 132-144.

MOZOONI, M., HERAVI, M., REJEH, N., RAHMANI, M., SHARIF NIA H. (2017). The effect of individual hope therapy program on reduction of depression in elderly patients with unstable angina hospitalized in cardiac care unit. J Crit Care Nurs, 10(4), 1-5.

OKANLI, A., KARABULUTLU, EY. (2011). Hemodiyaliz hastalarında hastalık algısının değerlendirilmesi. Anadolu Hemşirelik ve Sağlık Bilimleri Dergisi, 14(4),25-31.

ÖZ, F. (2010). Sağlık Alanında temel kavramlar. 2. Baskı. Ankara: Mattek Matbaacılık Basımevi; 58.

ÖZCAN, Y., BAŞTÜRK, M., ASLAN, S. S., UTAŞ C. (2000). Hemodiyaliz ve sürekli ayaktan periton diyalizi uygulanan hastalarda psikiyatrik morbidite ve yaşam kalitesi. Turgut Özal Tıp Merkezi Dergisi, 7(4), 333-337.

RAHIMIPOUR, M., SHAHGHOLIAN, N., YAZDANI, M. (2015). Effect of hope therapy on depression, anxiety and stress among the patients undergoing hemodialysis. Iran J Nurs Midwifery Res, 20(6), 694-699.

RAVAGHI, H., BEHZADIFAR, M., BEHZADIFAR, M., MIRGHAED, M. T., ARYANKHESAL, A., SALEMI, M., BRAGAZZI, N. L. (2017). Prevalence of depression in hemodialysis patients in Iran. Iran J Kidney Dis, 11(2), 90-98.

SAMAVI, S. A., NAJARPOURIAN, S., JAVDAN, M. (2018). The effectiveness of group hope therapy in labor pain and mental health of pregnant women. Psychol Rep, 0(0), 1-11.

SCHRANK, B., GRANT HAY, A. (2011). Hope and embitterment. Linden M, Maercker A, editors. Embitterment. $2011^{\text {th }}$ ed. Newyork: SpringerWien.

SHEKARABI-AHARI, G., YOUNESI, J., BORJALI, A., ANSARI-DAMAVANDI, S. (2012). The effectiveness of group hope therapy on hope and depression of mothers with children suffering from cancer in Tehran. Iran J Cancer Prev, 5(4), 183-188.

SNYDER, C. R. (1989). Reality negotiation from excuses to hope and beyond. J Soc Clin Psycbol, $8(2), 130-157$.

SNYDER, C. R. (1994). The psychology of hope: You can get there from here. New York: Free Press.

SNYDER, C. R. (2000). Handbook of Hope Theory, Measures and Applications. San Diego: Academic Press.

SNYDER, C. R. (2002). Hope theory: rainbows in the mind. PI. 13(4), 249-275. 
SNYDER, C. R., HARRIS, C., ANDERSON, J. R., HOLLERAN, S. A., IRVING, L. M., SIGMONT, S. T. vd. (1991). The will and the ways: development and validation of an individualdifferences measure of hope. J Pers Soc Psychol, 60(4), 570-585.

SNYDER, C. R., HOZA, B., PELHAM, W. E., RAPOFF, M., WARE, L., DANOVSKY, M. vd. (1997). The development and validation of the Children's Hope Scale. J Pediatr Psychol, 22(3), 399-421.

SNYDER, C. R., RAND, K. L., KING, E. A., FELDMAN, D. B., WOODWARD, J. T. (2002). False hope. J Clin Psychol, 58(9), 1003-1022.

SOTODEH- ASL, N., NESHAT- DUST, H. T., KALANTARI, M., TALEBI H., KHOSRAVI, A. R. (2010). Comparison of effectiveness of two methods of hope therapy and drug therapy on the quality of life in the patients with essential hypertension. J Clin Psychol, 2:1(5), $27-34$.

UMUT [Internet]. 2019. [Erişim Tarihi: 16.07.2020]. Erişim adresi: https://sozluk.gov.tr/.

YILDIRIM, N.K., OKANLI, A., KARABULUTLU, E.Y, KARAHISAR, F., ÖZKAN, S. (2013). Hemodiyaliz hastalarının anksiyete ve depresyon belirtilerine hastalık algısının etkisi: Çok merkezli bir çalışma. Anadolu Psikiyatri Dergisi, 14, 252-259.

YOUSEFI, A., RAFINIA, P., SABAHI, P. (2016). The effectiveness of hope therapy on quality of life in wives of veterans with post traumatic stress disorder. J Clin Psychol, 8:1(29), 1-10. 